\title{
Caracterização dendrológica e diafanização foliar de espécies da família lecythidaceae com interesse madeireiro
}

A família Lecythidaceae é uma das mais populosas nas florestas tropicais, tendo maior concentração na Floresta Amazônica principalmente pela capacidade adaptativa de suas flores. Tem alta importância econômica na região amazônica, apresentando 28 espécies com potencial madeireiro, porém, apesar de seu valor econômico poucos são os estudos sobre Lecythidaceae. Com o presente estudo objetivou-se realizar a caracterização macromorfológica do fuste, da arquitetura foliar e por meio da técnica de diafanização caracterizar o padrão de nervação das folhas de quatro espécies pertencentes à Lecythidaceae, quais sejam: Couratari stellata (A.C.Sm.), Eschweilera collina (Eyma), Eschweilera coriacea ((DC.) S.A. Mori) e Eschweilera pedicellata ((Rich.) S.A. Mori), coletadas na Floresta Nacional do Tapajós. Quantos aos caracteres avaliados para o fuste, os resultados obtidos foram: base reta (3) e base com sapopemas (1); aspecto do ritidoma sujo e áspero (4). Para a arquitetura foliar foram observados ápices do tipo acuminado (3), agudo (1); base arredondada (1), cuneada (2) e obtusa (1); margem inteira (3) e crenada (1). Em relação ao padrão de nervação foliar, todas as espécies apresentaram nervura primária do tipo pinada e nervuras secundárias do tipo broquidódroma. As características macromorfológicas em conjunto com o padrão de nervação auxiliam no processo de reconhecimento das espécies nos levantamentos florísticos.

Palavras-chave: Arquitetura foliar; Morfologia do fuste; Padrão de nervação; Levantamentos florísticos.

\section{Dendrological characterization and foliar diaphanization of species of the lecythidaceae family with timber interest}

\begin{abstract}
The Lecythidaceae family is one of the most populous in tropical forests, having greater concentration in the Amazon Forest mainly due to the adaptive capability of its flowers. It has a high economic importance in the Amazon region, presenting 28 species with timber potential, however, despite its economic value there are few studies about Lecythidaceae. The present study aimed to carry out the macromorphological characterization of the stem, leaf architecture and using the diaphanization technique to characterize the leaf nerve pattern of four species belonging to Lecythidaceae, which are Couratari stellata (A.C.Sm.), Eschweilera collina (Eyma), Eschweilera coriacea ((DC.) S.A. Mori) and Eschweilera pedicellata ((Rich.) S.A. Mori), collected in the Tapajós National Forest. As for the characters evaluated for the shaft, the obtained results were: straight base (3) and buttresses base (1); aspect of dirty and rough rhytidome (4). As for leaf architecture apexes acuminated (3), acute (1); round base (1) coined (2) and obtuse (1); entire margin (3) and crenate (1) were observed. Regarding the leaf nerve pattern, all species presented pinnate primary vein and bachidodrome secondary vein. The macromorphological characteristics in conjunction with the nerve pattern help in the process of species recognition in floristic surveys.
\end{abstract}

Keywords: Leaf architecture; Stem morphology; Nerve patterns; Floristic surveys.

Topic: Desenvolvimento, Sustentabilidade e Meio Ambiente

Reviewed anonymously in the process of blind peer
Received: 04/02/2021

Approved: 25/02/2021
Cristina Aledi Felsemburgh (iD

Universidade Federal do Oeste do Pará, Brasil

http://lattes.cnpq.br/8446110971099607

http://orcid.org/0000-0002-8199-8639

crisalefel@gmail.com

Nayane Paula de Sousa Figueira

Universidade Federal do Oeste do Pará, Brasil

http://lattes.cnpq.br/8081200958995187

nayanepaula.1993@gmail.com

Andressa Jaqueline Viana de Souza (iD

Universidade Federal do Oeste do Pará, Brasil

http://lattes.cnpq.br/1941608083658085

http://orcid.org/0000-0002-3632-124X

andressa-viana8@hotmail.com
Vanessa Holanda Righetti de Abreu (ic

Universidade Federal do Oeste do Pará, Brasil

http://lattes.cnpq.br/4665452925539605

http://orcid.org/0000-0002-2989-3151

vanessahra@yahoo.com.br
Referencing this:

FELSEMBURGH, C. A.; FIGUEIRA, N. P. S.; SOUZA, A. J. V.; ABREU, V. H. R.. Caracterização dendrológica e diafanização foliar de espécies da família lecythidaceae com interesse madeireiro. Revista Ibero Americana de Ciências Ambientais, v.12, n.2, p.448-456, 2021. DOI: http://doi.org/10.6008/CBPC2179-6858.2021.002.0039 


\section{INTRODUÇÃO}

Lecythidaceae é uma das famílias mais populosas nas florestas tropicais, especialmente em áreas pouco perturbadas e florestas não inundáveis com baixa altitude, tendo maior concentração na Floresta Amazônica. Segundo o projeto Flora do Brasil a família é composta geralmente por árvores de sub-bosque a emergentes e raramente arbustos ou lianas.

A família está descrita com cerca de 17 gêneros e 300 espécies (MATTA, 2011). Já Amorim et al. (2016) aponta a existência de 25 gêneros e 340 espécies, tendo o Brasil a ocorrência de 10 gêneros e 119 espécies pertencentes a Lecythidaceae, informações similares as encontradas no banco de dados do projeto Flora do Brasil 2020 que reconhece a ocorrência de 10 gêneros e 121 espécies no país.

Além do Brasil a família apresenta distribuição nas regiões tropicais da África, Madagascar, Ilhas Maurício, Ásia, Austrália, ilhas do Pacífico e nos Neotrópicos, porém, alcança o ápice de sua diversificação nas florestas de terra firma das Guianas e da Amazônia, mantendo baixa representatividade em regiões sazonalmente secas, com altitudes acima de $1000 \mathrm{~m}$ e solos oligotróficos (CATENACCI, 2015).

A explicação para a diversificação da família principalmente na Amazônia brasileira se dá por diversos fatores dentre eles ressalta-se a capacidade adaptativa das flores, explicada pelas respostas destas aos diferentes tipos de polinizadores, além da defesa de frutos e sementes tanto para predação natural quanto para auxílio no processo de dispersão (MATTA, 2011).Algumas espécies caracterizam-se pela presença de "envira ou embira" na casca (fibras), sendo esse um caractere do fuste e ramos utilizados para diagnóstico da família, folhas simples e alternas, , filotaxia alterna, margem inteira, às vezes serrilhada, sem estípulas significativas e sem a ocorrência de glândulas (RIBEIRO et al., 1999; JUDD et al., 2009; SAUERESSIG, 2018).

A ocorrência de espécies pertencentes a esta família vem sendo usada como indicador, por ecologistas e botânicos, de florestas preservadas uma vez que, em áreas onde houve perturbação por fogo os indivíduos pertencentes a Lecythidaceae não consegue se regenerar pois a queima inviabiliza as sementes e impede o rebrota (AZAMBUJA, 2012). Lecythidaceae também apresenta importância econômica na Amazônia onde 28 espécies da família são exploradas no comércio madeireiro (REIS et al., 2016).

Apesar de sua importância nas florestas tropicais, ainda é escasso o número de estudos sobre Lecythidaceae, sendo a família uma das quais apresenta dificuldades na determinação de suas espécies em campo e em herbário, uma vez que parte das espécies pertencentes a família apresenta identificação apenas até gênero, além das altas taxas de identificações equivocadas que contribuem para a propagação de informações taxonômicas errôneas acerca de suas espécies (MATTA, 2011).

Com base no supracitado e considerando que nem sempre é possível a coleta de material reprodutivo, objetivou-se com o presente estudo a caracterização macromorfológica do fuste, da arquitetura foliar e da descrição do padrão de venação por meio da técnica de diafanização foliar contribuir com informações vegetativas descritivas de quatro espécies da família botânica, que têm importância ecológica e econômica para o Brasil e, principalmente para a Região Amazônica. 


\section{MATERIAIS E MÉTODOS}

\section{Área de estudo}

O estudo foi realizado entre o período de junho a novembro de 2018. As amostras foliares foram coletadas na Floresta Nacional do Tapajós - Flona Tapajós, área de conservação florestal localizada no município de Belterra, Rodovia Santarém-Cuiabá (BR-163), km 67 (2 51’ Sul, 54 58’ Oeste). As análises microscópicas foram realizadas no Laboratório de Sementes Florestais - LSF situado no campus Tapajós da UFOPA. O clima local é do tipo Ami, quente e úmido, conforme a classificação climática de Köppen. Segundo dados do INMET (2019), no ano de 2018 a média anual de temperatura máxima foi de $31,3^{\circ} \mathrm{C}$ e a média anual de temperatura mínima de $20^{\circ} \mathrm{C}$ com umidade relativa superior a $80 \%$ durante todo o ano e média anual de precipitação de 206 milímetros $(\mathrm{mm})$. A área de estudo está situada em um planalto remanescente erosional antigo, quase plano, relevo ligeiramente ondulado, solo predominantemente do tipo Latossolo distrófico, e vegetação classificada como Floresta Ombrófila Densa, caracterizada pela incidência de indivíduos arbóreos de grande porte, lianas lenhosas, epífitas emergentes, palmeiras e com cobertura arbórea uniforme (AGUIAR et al., 2017; LIMA et al., 2018).

\section{Demarcação das árvores e coleta botânica}

As espécies da família Lecythidaceae foram selecionadas de acordo com o banco de dados do estudo 'Dinâmica do carbono na vegetação e nos solos ao longo do transecto do LBA', do projeto Experimento de Grande Escala da Biosfera - Atmosfera na Amazônia ('The Large Scale Biosphere - Atmosphere Experiment in Amazonia'), onde, os indivíduos avaliados no projeto já haviam sido identificados. As espécies selecionadas foram Couratari stellata (A.C.Sm.), Eschweilera collina (Eyma), Eschweilera coriacea (DC.) S.A. Mori) e Eschweilera pedicellata ((Rich.) S.A. Mori), sendo avaliados 4 indivíduos de cada espécie.

\section{Caracterização macromorfológica}

A caracterização macromorfológica do fuste foi realizada através de ficha dendrológica utilizando-se como referência o livro Flora da Reserva Ducke (RIBEIRO et al., 1999) e o livro Guia do Observador de Árvores (SILVA JUNIOR et al., 2014). O fuste dos espécimes foram analisados quanto a posição em relação ao solo (ereto ou inclinado), formato (circular, tortuoso, torcido, acanalado, arestado ou cristado e nodoso), formato da base (reta, dilatada, acanalada, com raízes escoras e sapopemas), aspecto da casca externa ou ritidoma (sujo e áspero, liso, rugoso, com placas lenhosas, com depressões, escamoso, estriado, fendido, fissurado, reticulado e lenticelado), coloração do ritidoma, resistência ao corte (rijo, médio ou frágil), cor da casca viva, cor do alburno, incidência de odor e presença de exsudato. Realizou-se a medida do diâmetro a altura do peito (DAP) em cm com uso de fita diamétrica.

\section{Caracterização da nervação foliar}

Para a descrição da nervação das folhas foi utilizada a metodologia de diafanização foliar, de acordo 
com o proposto por (PLOTZE, 2009). Finalizado o processo de diafanização, as amostras foliares foram montadas em lâminas de vidro e observadas em estereomicroscópio NOVA ZTX.

Os padrões foliares das nervuras foram descritos e classificados de acordo com o "Manual of Leaf Architecture" (ELLIS et al., 2009), sendo avaliados os tipos de nervuras, angulação das nervuras secundárias em relação à nervura primária, espaçamento entre nervuras secundárias, variação do ângulo das nervuras terciárias, tipo de areolação e tipo de F.E.V's (vênulas terminais livres).

\section{RESULTADOS}

Através da caracterização dendrológica em conjunto com a técnica de diafanização, observou-se variações na cor da casca viva, do alburno, no tipo de raiz, na morfologia das folhas e no padrão das nervuras secundárias, intersecundárias e terciárias das espécies avaliadas. Os indivíduos foram caracterizados de modo geral com formato de fuste circular, DAP médio de $25 \mathrm{~cm}$, fuste ereto em relação ao solo e aspecto do ritidoma sujo e áspero, exceto para espécies $E$. odora e $E$. ovata que apresentaram DAP médio de $70 \mathrm{~cm}$ e posição em relação ao solo tortuosa com aspecto do ritidoma escamoso.

\section{Couratari stellata (A.C.Sm.)}

A espécie $C$. stellata conhecida popularmente como 'tauari', foi caracterizada com fuste em formato circular, ereto em relação ao solo, ritidoma de aspecto sujo e áspero, coloração marrom avermelhado, base reta, casca viva com tonalidade creme e alburno de coloração amarelo intenso. Folhas com limbo no formato obovado, ápice agudo, base cuneada e margem crenada. Padrão de nervura do tipo pinada, nervuras secundárias broquidódromas, 8-30 pares, nervuras intersecundárias fracas, espaçamento entre nervuras secundárias irregular com ângulos uniformes e ângulo das nervuras terciárias decrescendo exmedialmente (Figuras 1-6).

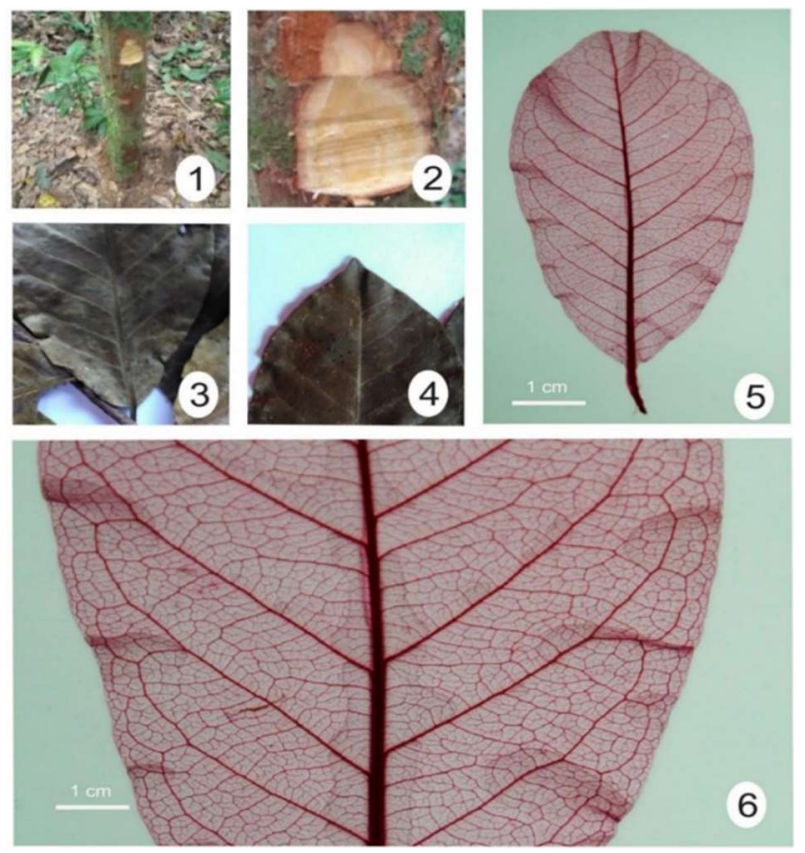

Figura 1-6. Aspectos dendrológicos e arquitetura foliar de $C$. stellata 


\section{Eschweilera collina (Eyma)}

Espécie conhecida popularmente como 'mata-mata vermelho' na região da FLONA Tapajós, foi caracterizada com fuste em formato circular, ereto em relação ao solo, ritidoma com aparência suja e áspera e de cor marrom avermelhada, coberto por musgos, base da árvore reta, casca viva avermelhada, com camadas longitudinais e alburno rosado. Folhas com limbo elíptico, ápice acuminado, base arredondada e margem inteira. Nervura primária pinada, nervuras secundárias broquidódromas, 11-14 pares, nervuras intersecundárias fortes, espaçamento irregular entre nervuras secundárias, ângulo uniforme e nervuras terciárias com ângulos inconsistentes (Figuras 7 - 12).
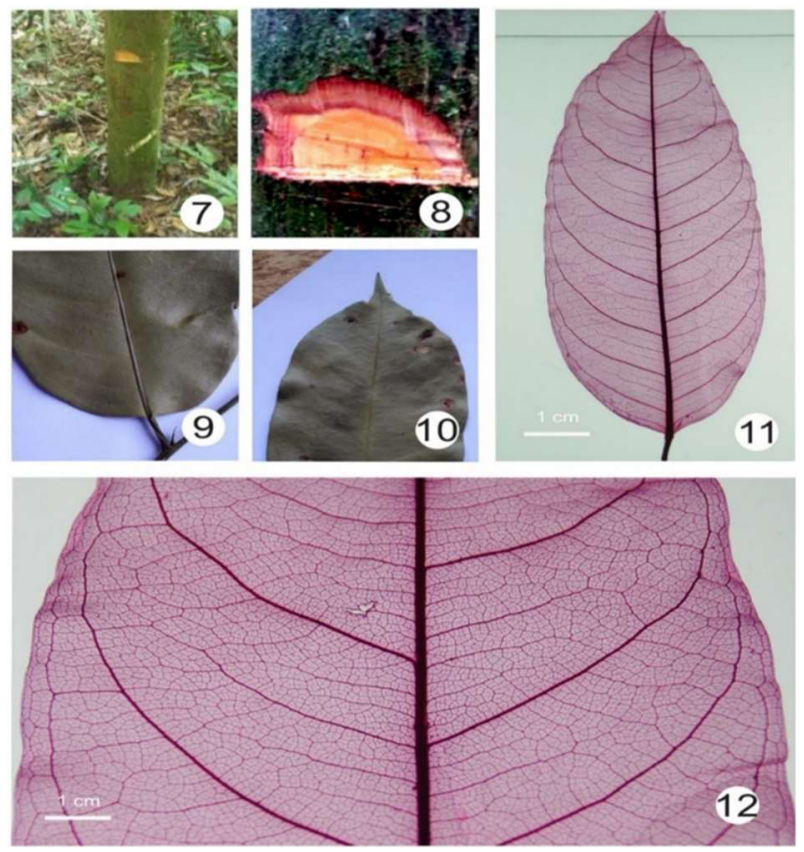

Figura 7-12. Aspectos dendrológicos e arquitetura foliar de E. collina

\section{Eschweilera coriacea (Mori, Scott A)}

Conhecida popularmente como 'mata-mata-branco', caracterizada com fuste de formato circular, ereto, ritidoma sujo e áspero, de cor cinza e recoberto por musgos, base com sapopemas. Casca viva e alburno de cor amarelo intenso, havendo pouca distinção entre essas duas partes. As folhas são elípticas, com ápice acuminado, base cuneada e margem foliar inteira, nervura primária pinada, nervuras secundárias broquidódroma, com 13-20 pares, nervuras intersecundárias fortes, espaçamento entre nervuras secundárias irregular, com ângulo aumentando em direção à base, nervuras terciárias reticuladas com ângulos inconsistentes (Figuras 13 - 18). 

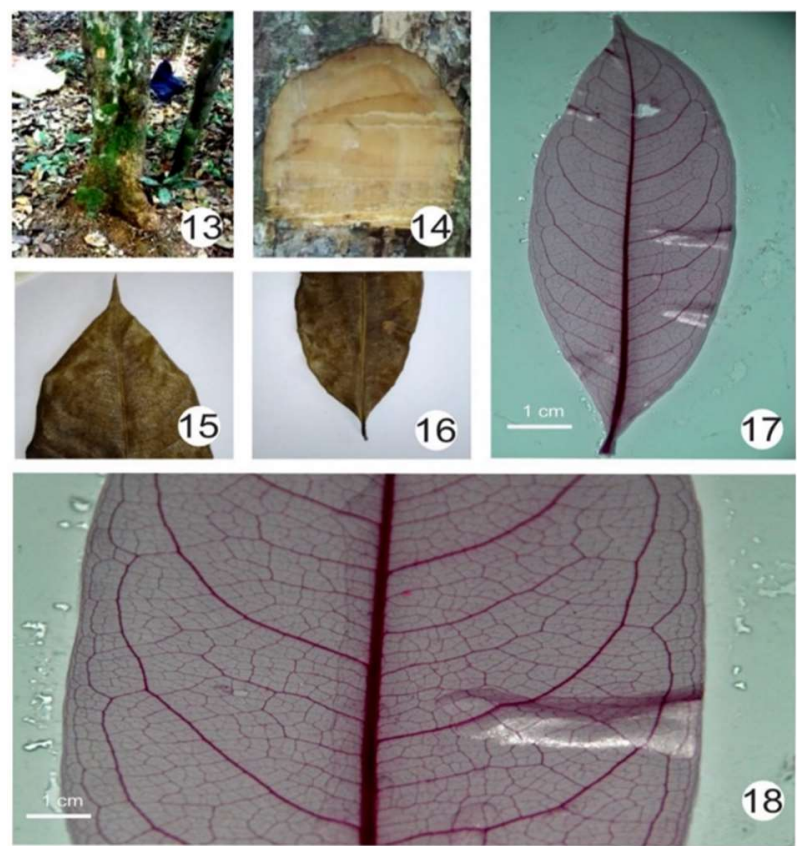

Figura 13-18. Aspectos dendrológicos e arquitetura foliar de E. coriaceae

\section{Eschweilera pedicellata (Rich.) S.A. Mori}

Conhecida como 'mata-mata branco', a espécie foi caracterizada com fuste formato circular, ereto em relação ao solo, base reta, ritidoma sujo e áspero, com coloração marrom avermelhado e incidência de musgos, casca viva cor creme e alburno creme. Folhas com limbo elíptico, ápice acuminado, base obtusa, com margem foliar inteira, nervura primária pinada, nervuras secundárias broquidódroma, 7-14 pares, nervuras intersecundárias fortes, espaçamento entre as nervuras secundárias irregular, ângulos das nervuras secundárias aumentando em direção a base e nervuras terciárias reticuladas com ângulos inconsistentes (Figuras 19 - 24). Com as características macromorfológicas do fuste e das folhas foi possível elaborar uma chave de identificação das espécies observadas, exibida no quadro 1.
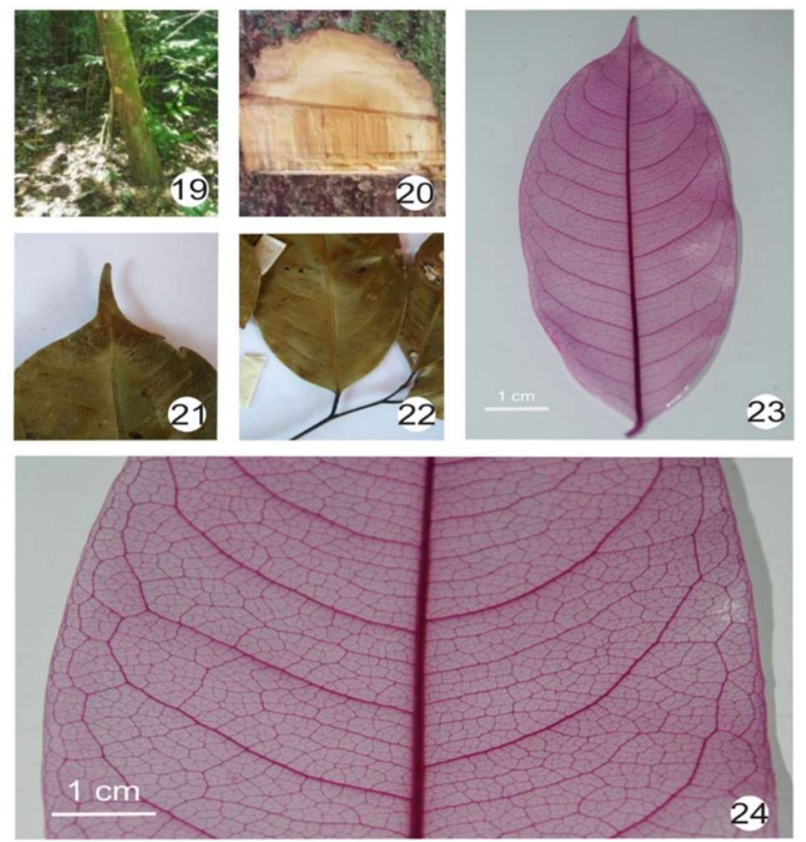

Figura 19-24. Aspectos dendrológicos e arquitetura foliar de E. pedicellata 
Quadro 1: Chave de características de fuste, folha e nervura.

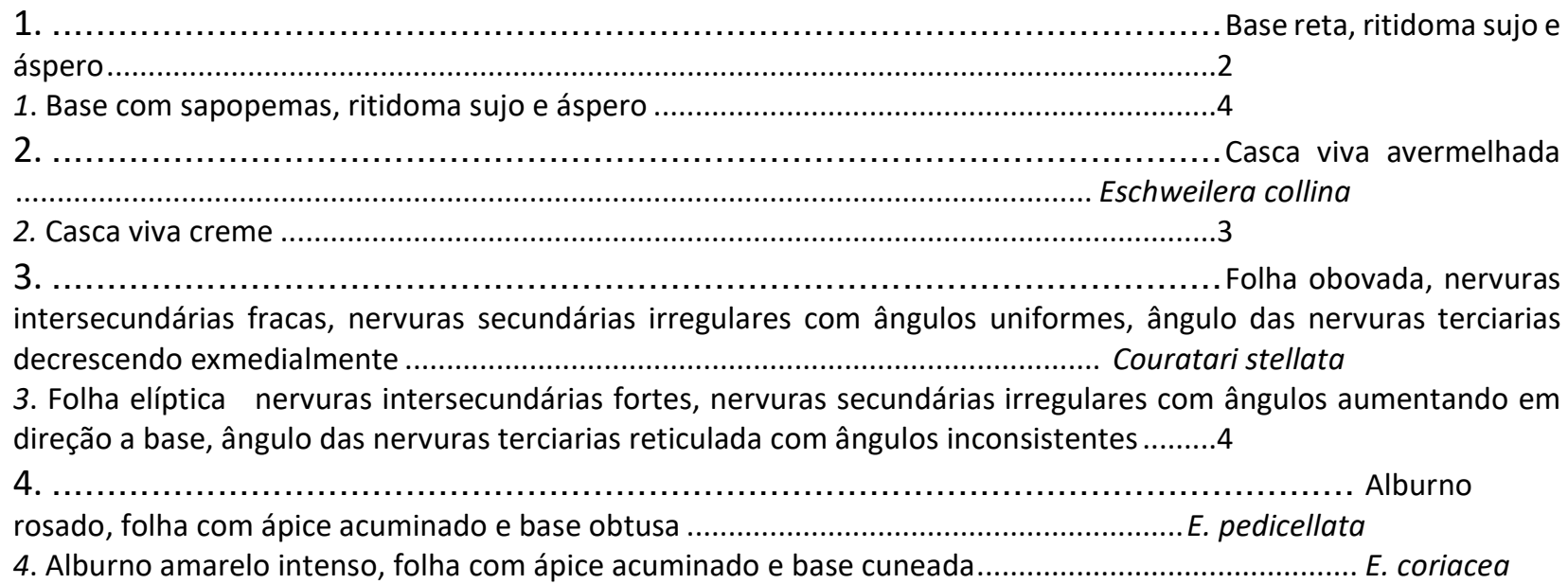

\section{DISCUSSÃO}

Segundo Procópio et al. (2008) a espécie C. stellata é reconhecida por apresentar características macromorfológicas marcantes como a presença de sapopemas assimétricas e ritidomas com fissuras superficiais, reticuladas. Nos espécimes de $C$. stellata avaliados nesse estudo não se observou a presença de sapopemas basais e por não ter de um caractere que definisse de forma majoritária sua aparência, apesar da presença de fissuras superficiais que ocorreram de forma esparsa e pouco definidas, seu ritidoma foi caracterizado como sujo e áspero.

A ausência de sapopemas basais e o aspecto do ritidoma podem estar relacionados com a idade dos espécimes avaliados na área de estudo, uma vez que se tratava de indivíduos jovens. Os sapopemas basais tendem a aparecer nos espécimes de acordo com seu amadurecimento, assim como pode ocorrer com a aparência do ritidoma de algumas espécies. Matta (2011) em estudos com espécimes de Eschweilera amazônica observou que indivíduos jovens desta espécie apresentavam ritidoma liso enquanto em plantas mais velhas o ritidoma foi caracterizado como fissurado.

Para a espécie $E$. collina, encontrou-se similaridades e diferenças na caracterização feita por Mori et al. (1995) que definiram indivíduos de E. collina como árvores de dossel, casca lisa com lenticelas orientadas verticalmente e marcas ocasionais de argola, casca interna laranja a marrom avermelhado, folhas elípticas a amplamente elípticas, cartáceas, glabras com 6-10 pares de nervuras laterais, base obtusa a aguda, ápice geralmente acuminado curto, as vezes longo acuminado.

As características encontradas neste estudo para E. coriaceae são semelhantes às encontradas por Matta (2011), no entanto, em relação ao aspecto do ritidoma os espécimes observados pelo autor apresentavam o ritidoma com lenticelas verticais, podendo estar essa característica relacionada com a idade dos espécimes, pois, de acordo com Ribeiro et al. (1999) a presença de lenticelas é comum em indivíduos adultos.

Para a espécies E. pedicellata os caracteres avaliados nesse estudo são similares ao que Catenacci (2015) observou para E. pedicellata em levantamento de indivíduos pertencentes à família Lecythidaceae na região do alto Rio Madeira no estado de Rondônia. Segundo o autor, esta espécie é de sub-bosque facilmente 
reconhecida pela casca externa castanho avermelhada e casca interna creme e por não possuir sapopemas como E. coriacea, que também é conhecida pelo nome popular de 'mata-mata branco' na região da Floresta Nacional do Tapajós.

Como observado com E. pedicellata e E. coriaceae, o fato de duas ou mais espécies serem conhecidas pelo mesmo nome vernacular pode omitir a diversidade correta de uma área florestal acarretando a venda de espécies distintas e com propriedades mecânicas e químicas diferentes (PROCÓPIO et al., 2008), ressaltando a importância da identificação botânica correta dos indivíduos arbóreos em inventários florísticos.

Através da observação das nervuras das folhas das espécies foi possível observar sutis diferenças que possibilitaram diferenciá-las juntamente com os caracteres macromorfológicos, dentre estas citam-se o número de pares de nervuras secundárias e os ângulos das nervuras secundárias em relação a veia primária, como ao se analisar comparativamente o padrão de nervação das espécie e $C$. stellata, E. collina e $E$. pedicellata, onde o ângulo das nervuras secundárias em relação a nervura primária têm um padrão uniforme na espécie $E$. collina, enquanto em E. coriacea o padrão dos ângulos das nervuras secundárias diminuem em direção a base, e em E. pedicellata aumentam em direção a base da folha.

\section{CONCLUSÕES}

A caracterização dendrológica em conjunto com as informações sobre o padrão de nervação foliar possibilitaram uma rápida diferenciação entre espécies com aspectos similares e indivíduos de uma mesma família botânica (SOUZA et al., 2019), auxiliando de forma eficiente o reconhecimento de espécies pertecentes à famílias como a Lecythidaceae, que não possuem caracteres fortes em sua identificação, como incidência de estípulas, gomas, dentre outros.

\section{REFERÊNCIAS}

AGUIAR, D. R.; GAMA, J. R. V.; BELDINI, T. P.. Estoque de carbono por grupo ecológico na Floresta Nacional do Tapajós. Espacios, Caracas, v.38, n.32, p.21, 2017.

AZAMBUJA, C. A. P.. As Lecythidaceae Poit. no Parque Nacional do Viruá (Roraima). Dissertação (Mestrado em Ciências Biológicas com ênfase em botânica) - Instituto Nacional de Pesquisa da Amazônia, Manaus, 2012.

CATENACCI, F. S.. Lecythidaceae poit. na região do alto Rio Madeira, Rondônia. Dissertação (Mestrado em Botânica) Universidade de Brasília, Brasília, 2015.

ELLIS, B.; DALY, D. C.; HICKEY, L. J.; JOHNSON, K. R.; MITCHELL, J. D.; PETER, W.; WING, S. L.. Manual of leaf architecture. Ithaca: Cornell University Press, 2009.

INMET. Instituto Nacional de Meteorologia. Dados de rede do INMET, 2019.

JUDD, W. S.; CAMPBELL, C. S.; KELLOGG, E. A.; STEVENS, P. F.; DONOGHUE, M. J.. Sistemática vegetal: um enfoque filogenético. 3 ed. Porto Alegre: Artmed, 2009.
LIMA, B. A.; ALMEIDA, B. R. S.; SOUSA, E. A. B.; MELO, M. B.; MELO, L. O.; COSTA, D. L.; SANTOS, M. F.. Estrutura e dinâmica florestal sob efeito do manejo madeireiro na FLONA Tapajós. Advance in Forestry Science, Cuiabá, v.5, n.4, p.437-443, 2018.

MATTA, L. B. V.. As Lecythidaceae Poit. na Reserva de desenvolvimento sustentável do Tupé. Dissertação (Mestrado em Ciências Biológicas com ênfase em botânica) Instituto Nacional de Pesquisa da Amazônia, Manaus, 2011.

MORI, S. A.; LEPSCH-CUNHA, N.. The Lecythidaceae of a central Amazonian moist forest. Nova York: The New York Botanical Garden Press, 1995.

PLOTZE, R. O.. Visão artificial e morfometria na análise e classificação de espécies biológicas. Tese (Doutorado em Ciências da computação e Matemática computacional) Instituto de Ciências Matemáticas e Computação, São Carlos, 2006. DOI: http://doi.org/10.11606/T.55.2010.tde15042010-105936

PROCÓPIO, L. C.; SECCO, R. S.. A importância da identificação botânica nos inventários florestais: o exemplo do "tauari" 
(Couratari spp. e Cariniana spp. - Lecythidaceae) em duas áreas manejadas no estado do Pará. Acta Amazônica, Manaus, v.38, n.1, p.31-44, 2008.

RIBEIRO, J. E. L.; HOPKINS, M. J. G.; VICENTINI, A.; SOTHERS, A. C.; COSTA, M. A.; BRITO, J. M.; SOUZA, M. A. D.; MARTINS, L. H. P.; LOHMANN, L. G.; ASSUNÇÃO, P. A. C. L.; PEREIRA, E. C.; SILVA, C. F.; MESQUITA, M. R.; PROCÓPIO, L. C.. Flora da Reserva Ducke: Guia de identificação das plantas vasculares de uma floresta de terra-firme na Amazônia Central. Manaus: Instituto Nacional de Pesquisas da Amazônia, 1999.

SAUERESSIG, D.. Manual de dendrologia: o estudo das árvores. 2 ed. Irati: Plantas do Brasil, 2018.

SILVA JUNIOR, M. C.; SILVA, L. H. S.; CORDEIRO, A. O. O.; MUNHOZ, C. B. R.. Guia do observador de árvores: tronco, copa e folha. Brasília: Rede de Sementes do Cerrado, 2014.

SOUZA, A. J. V.; FELSEMBURGH, C. A.; PELEJA, V. N.; SOUZA, S. A.. Levantamento quantitativo e caracterização dendrológica no campus Tapajós da Universidade Federal do Oeste do Pará. Revista Ibero-Americana de Ciências Ambientais, Aracaju, v.10, n.1, p.297-313, 2019. DOI: https://doi.org/10.6008/CBPC2179-6858.2019.001.0025

A CBPC - Companhia Brasileira de Produção Científica (CNPJ: 11.221.422/0001-03) detém os direitos materiais desta publicação. Os direitos referem-se à publicação do trabalho em qualquer parte do mundo, incluindo os direitos às renovações, expansões e disseminações da contribuição, bem como outros direitos subsidiários. Todos os trabalhos publicados eletronicamente poderão posteriormente ser publicados em coletâneas impressas sob coordenação da Sustenere Publishing, da Companhia Brasileira de Produção Científica e seus parceiros autorizados. Os (as) autores (as) preservam os direitos autorais, mas não têm permissão para a publicação da contribuição em outro meio, impresso ou digital, em português ou em tradução. 